Evaluation of Design Standards of Four-Hour-Volume Traffic Signal Warrant.

Author(s): Xuesong Zhu, Albert Gan, and David Shen

Source: Journal of the Transportation Research Forum, Vol. 49, No. 3 (Fall 2010),

pp. 7-19

Published by: Transportation Research Forum

Stable URL: http://www.trforum.org/journal

The Transportation Research Forum, founded in 1958, is an independent, nonprofit organization of transportation professionals who conduct, use, and benefit from research. Its purpose is to provide an impartial meeting ground for carriers, shippers, government officials, consultants, university researchers, suppliers, and others seeking exchange of information and ideas related to both passenger and freight transportation. More information on the Transportation Research Forum can be found on the Web at www.trforum.org. 


\title{
Evaluation of Design Standards of Four-Hour- Volume Traffic Signal Warrant
}

\author{
by Xuesong Zhu, Albert Gan, and David Shen
}

Traffic signal warrants set the minimum conditions under which a traffic signal installation may be appropriate. The four-hour volume signal warrant in the current Manual on Uniform Traffic Control Devices (MUTCD) (FHWA 2009) is applied based on a set of critical vehicular volumes for different lane combinations of major and minor streets. This paper describes an effort to apply microscopic simulation to evaluate the critical volumes used in the four-hour warrant. The results show significant differences in average control delay for minor street traffic under different volume combinations, lane configurations, turning volume percentages, heavy vehicle percentages, and the number of major street lanes (four versus six lanes), most of which are not currently considered in the four-hour warrant. This finding provides some evidence of the need to possibly revise the critical design values of the current four-hour volume warrant.

\section{INTRODUCTION}

Traffic signal warrants provide the threshold conditions under which a traffic signal installation may be appropriate. The current version of the Manual on Uniform Traffic Control Devices (MUTCD) (FHWA 2009), which serves as the national standard for the application of traffic control devices, includes the following eight warrants: (1) eight-hour vehicular volume, (2) four-hour vehicular volume, (3) peak-hour volume, (4) pedestrian volume, (5) school crossing, (6) coordinated signal system, (7) crash experience, and (8) roadway network. Collectively, these warrants are designed to consider different conditions under which signal control is found to be a justifiable measure for the safer and more efficient operation of an intersection.

Figure 1 shows the curves representing the critical vehicular volumes for four different lane combinations of major and minor streets for low-speed (i.e., less than $40 \mathrm{mph}$ for major street approach) roadways. The figure shows one curve fewer than the number of lane configurations, as two of the four configurations share the same curve. A similar set of standards with lower critical vehicular volumes is used for higher-speed (above $40 \mathrm{mph}$ ) roadways or for communities with a population below 10,000. The four-hour warrant is met when, in each of any four hours of an average day, the plotted point representing vehicles per hour on the major street (including the total of both approaches) and the corresponding vehicles per hour on the higher volume minor street approach fall above the critical curve for the corresponding lane configuration at the location under study.

\section{LITERATURE REVIEW}

Minimum vehicular volumes were generally used in warranting installation of a traffic signal. The origin of the four-hour warrant is found to be based on a large number of curves developed as a part of the Cooperative Research Panels Highway (NCHRP) project. These curves obtained consensus agreement among practicing traffic engineers before being included into MUTCD. Texas developed a graphic form of the four-hour warrant. This warrant, adopted by MUTCD in 1985 and continuously modified ever since, evolves into the current four-hour warrant.

Despite the widespread use, there are some concerns regarding this vehicular volume warrant. Sampson (1999) believed that warrants based on fixed vehicular volumes were inflexible and not often accepted by political decision makers. TTI (2001) recommended a reduction factor to be 
Figure 1: Four-Hour Warrant for Normal Conditions

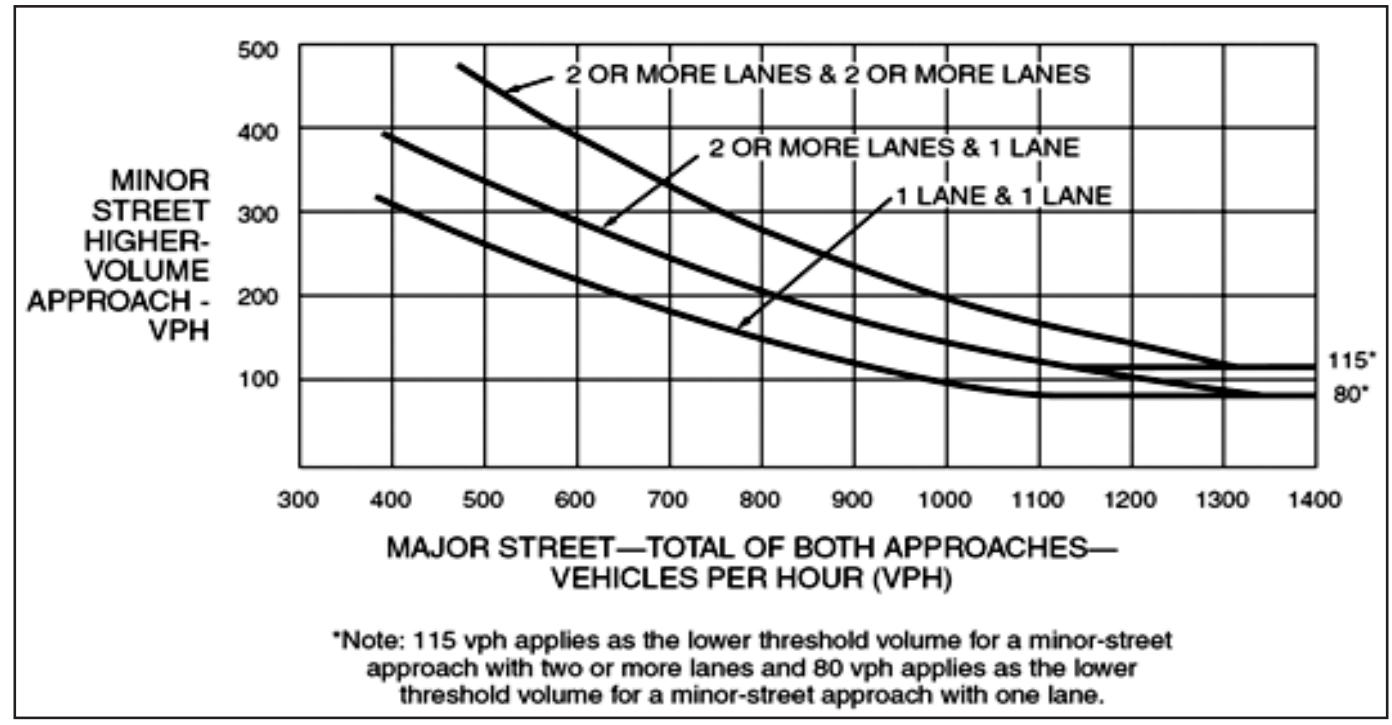

applied when vehicular volume based warrants are used to warrant the installation of a traffic signal at an intersection with pedestrian trip generators (e.g., activities center, pedestrian transportation facilities).

Researchers have been using simulation of intersection volume to assess the warranting of a traffic signal. Kell (1963) used a computer simulation to compare total delay between a pre-timed signalized intersection and a two-way stop controlled intersection. Park et al. (2000) employed Monte Carlo simulation to generate the probability that a particular traffic signal warrant can be met at an intersection. Recent advances in traffic simulation software offer the opportunity to effectively evaluate the appropriateness of critical volume standards set forth in the four-hour volume warrant more than two decades ago.

An important objective that the standards should strive to achieve is the reasonableness of the traffic conditions experienced by minor street traffic under different combinations of volumes and lane configurations. Critical volumes that result in inconsistent or unreasonable driver experiences for minor street traffic could possibly lead to either unwarranted or overlooked intersections, causing intersections with a lesser need for signalization to be selected for signal installation over intersections that have a greater need for these measures. This paper presents a study to evaluate the performance of the critical curves currently used in the four-hour warrant for low-speed conditions, often referred to as "normal conditions." Specifically, the study includes the following five evaluations:

1. The performance consistency along each critical curve and among the curves.

2. The appropriateness of sharing a critical curve for: (1) two or more lanes major and onelane minor; and (2) one-lane major and two or more lanes minor.

3. The appropriateness of sharing the same critical curve for two and three lanes.

4. The impact of different turning volume percentages on minor street vehicles.

5. The impact of different heavy vehicle percentages on minor street vehicles.

The findings of the paper should provide academic researchers preliminary evidence of the need to revisit the current standards in the four-hour warrant. Practicing traffic engineers may use the findings to further investigate the appropriateness of applying four-hour warrant in their justification of signal installation. 


\section{METHODOLOGY OVERVIEW}

The general methodology consists of the following four steps:

1. Select the appropriate measure of effectiveness (MOE) that can best measure the quality of operation for minor street traffic.

2. Identify the simulation model input data, which are vehicular volumes combinations obtained from the critical curves in the four-hour warrant.

3. Develop the simulation models for different volume combinations, turning traffic percentages, and heavy vehicle percentages under different lane configurations.

4. Analyze the simulation results and evaluate the critical volume curves based on the selected MOE.

\section{MEASURE OF EFFECTIVENESS}

Potential MOEs for measuring the operation of an unsignalized intersection can include delay, stop, fuel consumption, and average speed. It is reasonable to assume that favorable MOE values will lead to a better safety experience at intersections. In this study, control delay in seconds per vehicle $(\mathrm{s} / \mathrm{veh})$ for the minor street approach is selected as the MOE. Control delay is the component of delay that results from the type of control at the intersection. It is the difference between the travel time that would have occurred in the absence of the intersection control and the travel time that results because of the presence of the intersection control. Control delay includes initial deceleration delay, queue move-up time, stopped delay, and final acceleration delay. Control delay is the measure used in the Highway Capacity Manual (TRB 2000) to determine the level of service, and is commonly used as the measure to gauge driver satisfaction at both signalized and unsignalized intersections (Al-Omari and Benekohal 1999, Chandra et al. 2009).

\section{MODEL INPUT DATA}

Table 1 provides the critical volume combinations obtained from the three curves in Figure 1. These data are stratified by the proceeding five lane configurations (per direction as shown in Figure 2):

1. Major street has one lane and minor street has one lane.

2. Major street has one lane and minor street has two lanes.

3. Major street has two lanes and minor street has one lane.

4. Major street has two lanes and minor street has two lanes.

5. Major street has three lanes and minor street has one lane. 
Traffic Signal Warrant

Figure 2: Five Lane Configurations Represented in Four-hour Warrant Curves

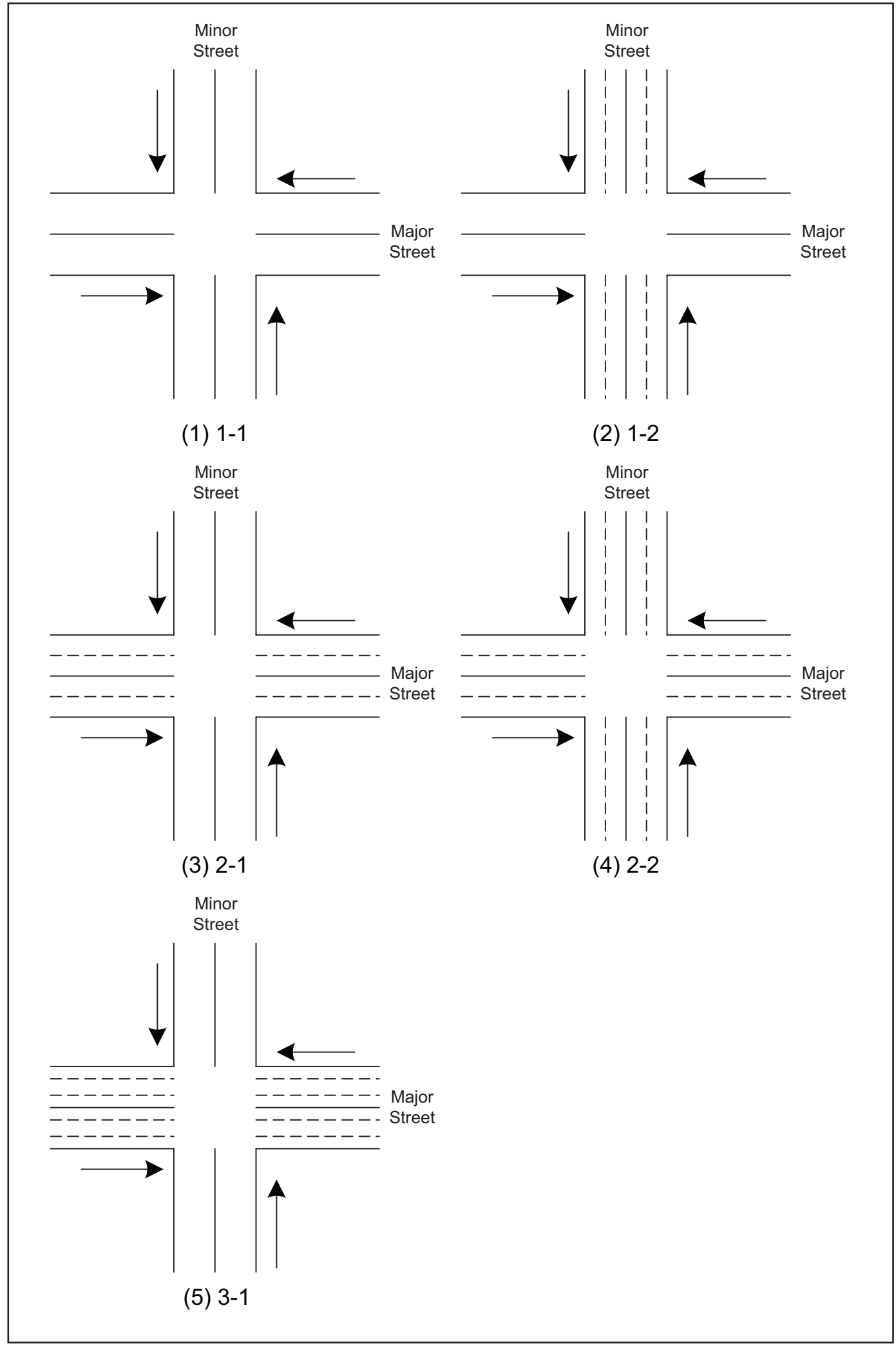


Table 1: Critical Traffic Volumes (vph) for "Normal Conditions" (from Critical Curves)

\begin{tabular}{|c|c|c|c|c|c|c|c|c|c|c|}
\hline \multirow{3}{*}{$\begin{array}{l}\text { Point from } \\
\text { Critical } \\
\text { Curves }^{\mathrm{a}}\end{array}$} & & & \multicolumn{6}{|c|}{ Traffic Volumes on Major and Minor Streets (vph) } & & \\
\hline & \multicolumn{2}{|c|}{$\begin{array}{l}1 \text { Lane Major } \\
\text { and } 1 \text { Lane } \\
\text { Minor (1-1) }\end{array}$} & \multicolumn{2}{|c|}{$\begin{array}{l}1 \text { Lane Major } \\
\text { and } 2 \text { Lanes } \\
\text { Minor }(1-2)^{\mathrm{b}}\end{array}$} & \multicolumn{2}{|c|}{$\begin{array}{l}2 \text { Lanes Major } \\
\text { and } 1 \text { Lane } \\
\text { Minor }(2-1)^{\mathrm{b}}\end{array}$} & \multicolumn{2}{|c|}{$\begin{array}{c}2 \text { Lanes Major } \\
\text { and } 2 \text { Lanes } \\
\text { Minor }(2-2)\end{array}$} & \multicolumn{2}{|c|}{$\begin{array}{l}3 \text { Lanes Major } \\
\text { and } 1 \text { Lane } \\
\text { Minor }(3-1)^{\mathrm{b}}\end{array}$} \\
\hline & Major & Minor & Major & Minor & Major & Minor & Major & Minor & Major & Minor \\
\hline 1 & 500 & 260 & 500 & 340 & 500 & 340 & 500 & 450 & 500 & 340 \\
\hline 2 & 600 & 220 & 600 & 290 & 600 & 290 & 600 & 390 & 600 & 290 \\
\hline 3 & 700 & 180 & 700 & 250 & 700 & 250 & 700 & 330 & 700 & 250 \\
\hline 4 & 800 & 150 & 800 & 210 & 800 & 210 & 800 & 280 & 800 & 210 \\
\hline 5 & 900 & 125 & 900 & 180 & 900 & 180 & 900 & 240 & 900 & 180 \\
\hline 6 & 1000 & 95 & 1000 & 150 & 1000 & 150 & 1000 & 195 & 1000 & 150 \\
\hline 7 & 1100 & 80 & 1100 & 130 & 1100 & 130 & 1100 & 170 & 1100 & 130 \\
\hline 8 & 1200 & 80 & 1200 & 115 & 1200 & 100 & 1200 & 150 & 1200 & 100 \\
\hline 9 & 1300 & 80 & 1300 & 115 & 1300 & 90 & 1300 & 115 & 1300 & 90 \\
\hline 10 & 1400 & 80 & 1400 & 115 & 1400 & 80 & 1400 & 115 & 1400 & 80 \\
\hline
\end{tabular}

Notes:

${ }^{\text {a }}$ Points selected from Critical Curves shown in Figure 1.

${ }^{\mathrm{b}}$ The volume combinations for these lane configurations were obtained from the same curve, thus the volumes are the same except for (2-1), in which $115 \mathrm{vph}$ on Minor Street is used for points 8, 9 and 10.

For ease of reference, these five lane configurations are labeled as 1-1, 1-2, 2-1, 2-2, and 3-1, respectively. For example, 1-1 represents the combination of one-lane major street and one-lane minor street. It is noted here that the current standard has the three-lane configurations, 1-2, 2-1, and 3-1, sharing the same curve.

Each point on the curve represents a combination of major street and minor street volumes. The major street volume is the sum of both approaches and the minor street volume represents the higher volume of the two minor street approaches. In the simulation, the volumes for each of the four approaches must be specified. For evaluation purposes, the two major approach volumes are assumed to be equal and the lower minor street approach volume is assumed to be equal to $80 \%$ of the higher minor street approach volume. Additionally, to evaluate the influence of the turning traffic percentages, the following three turning percentages, expressed as left-turn $\%$, through $\%$, right-turn \%, were used: $(10 \%, 80 \%, 10 \%),(20 \%, 60 \%, 20 \%)$, and $(40 \%, 20 \%, 40 \%)$.

\section{SIMULATION MODELING}

\section{Simulation Tool}

CORSIM (CORridor SIMulation) was used to simulate the different traffic scenarios and to obtain the corresponding MOE in this study. CORSIM is a microscopic simulation model and is capable of modeling traffic and traffic control conditions on both surface streets and freeway networks (ITT Systems and Sciences Corporation 1998). A microscopic simulation model is a definition relative to its macroscopic counterpart. A microscopic simulation model details the movement of individual vehicles, and traffic information associated with individual vehicles can be analyzed. First developed by the U.S. Department of Transportation in the 1970s, CORSIM has become a commonly used and accepted simulation model in the United States. CORSIM was designed to represent traffic flow on a roadway system using these commonly accepted driver and vehicle behavior models: (1) NETSIM, a microscopic stochastic simulation model for street networks, and (2) FRESIM, a microscopic stochastic simulation model for freeway networks. Furthermore, an important element 
of TSIS (Traffic Software Integrated System) is the TRAFVU (TRAF Visualization Utility) output processor, which allows the user to graphically view network and traffic operations.

\section{Network Coding}

CORSIM is based on a link-node network model. In this model, roadway segments are represented by links and intersections are represented by nodes. Figure 3 shows the link-node diagram of the base network used in this study. This base network was modified for different lane configurations, volume combinations, left- and right-turn percentages, and heavy vehicle percentages to simulate different geometric and traffic scenarios.

\section{Figure 3: Link-Node Diagram of Base Network}

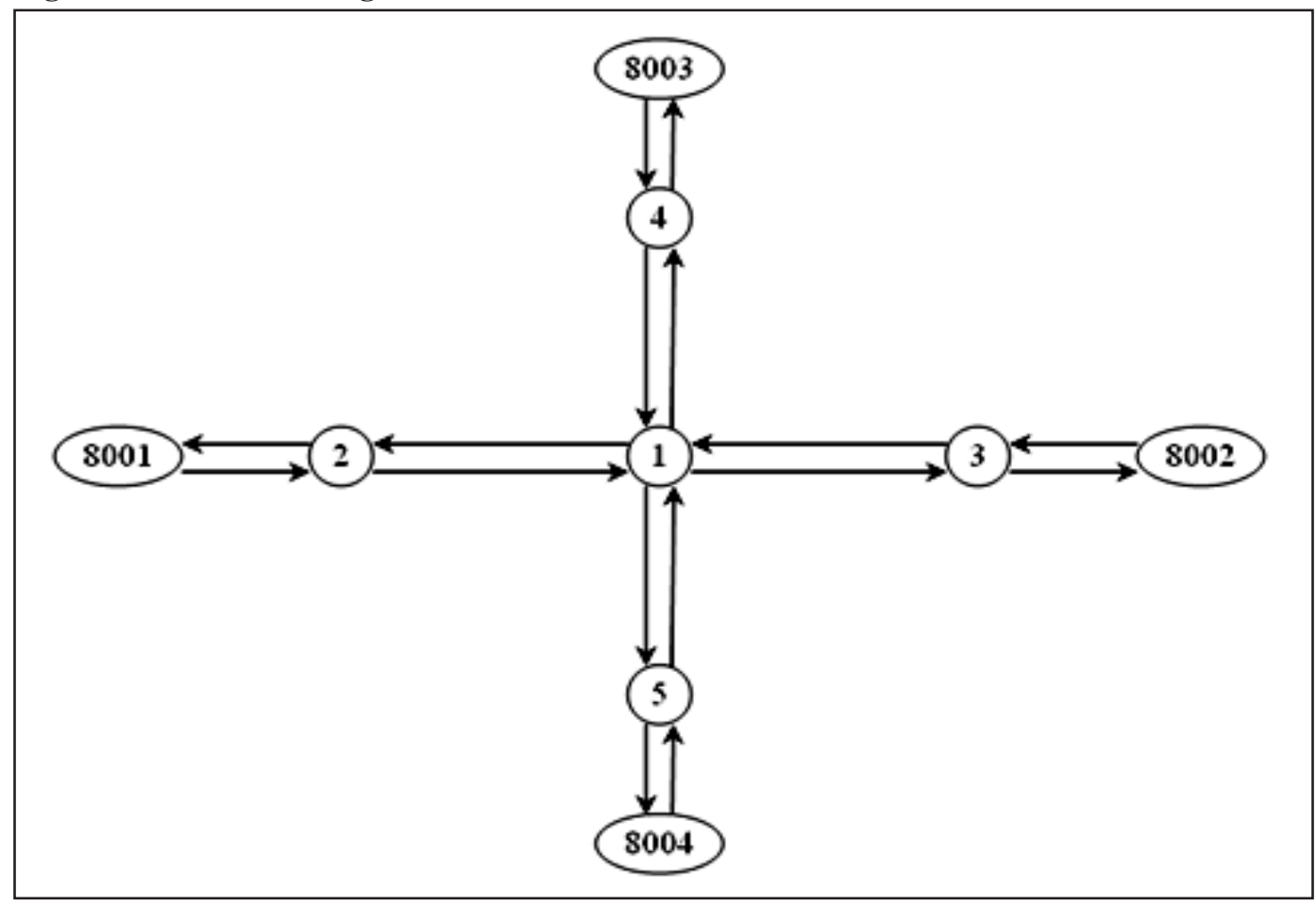

\section{Simulation Runs}

After the CORSIM input file for the base network was coded, simulation runs for different scenarios were performed by modifying the base input file. Table 1 shows a total of 50 volume combinations for the three four-hour warrant curves. To perform the necessary analysis, three turning traffic volume percentages were then taken into account to yield a total of 150 simulation scenarios. In these 150 scenarios, the heavy vehicle percentages are assumed to be $5 \%$. To evaluate the effect of different heavy vehicle percentages on minor street delay, another 60 scenarios based on the more common 2-1 lane configuration were created. These 60 scenarios are stratified by three different turning percentages and two different heavy vehicle percentages (10\% and $20 \%)$. Therefore, a total of 210 scenarios were created.

To simulate "normal" conditions (i.e., major street approach speeds of up to $40 \mathrm{mph}$ ), the freeflow speed on the major street is set at $35 \mathrm{mph}$. Due to the stochastic nature of simulation models, simulation runs based on different random numbers may produce significantly different results. Five to 10 simulation replications have been commonly used in traffic simulation studies. In this study, 
10 replications were performed for each scenario, which results in a total of 2,100 simulation runs. The traffic delays from the 10 replications were then averaged to obtain the final average for each scenario.

\section{Simulation Outputs}

The simulated average control delays for the 150 scenarios ( $5 \%$ heavy vehicle percentage) are given in Table 2. The results are stratified by the five different lane configurations, three turning volume percentages, and 10 volume combinations. Table 3 gives the simulated average control delays for another 60 scenarios stratified by different left- and right-turning percentages for two additional heavy vehicle percentages $(10 \%$ and $20 \%)$.

Table 2: Average Minor Street Control Delays (seconds per vehicle, s/veh) for 150 Scenarios at $5 \%$ Heavy Vehicles

\begin{tabular}{|c|c|c|c|c|c|c|c|c|c|c|c|c|c|c|}
\hline \multirow{3}{*}{$\begin{array}{c}\text { Point from } \\
\text { Critical } \\
\text { Curves }\end{array}$} & \multicolumn{14}{|c|}{ Average Minor Street Control Delays (s/veh) } \\
\hline & \multicolumn{3}{|c|}{$\begin{array}{c}1 \text { Lane Major } \\
\text { and } \\
1 \text { Lane Minor } \\
(1-1)\end{array}$} & \multicolumn{3}{|c|}{$\begin{array}{c}1 \text { Lane Major } \\
\text { and } \\
2 \text { Lanes Minor } \\
(1-2)\end{array}$} & \multicolumn{3}{|c|}{$\begin{array}{c}2 \text { Lanes Major } \\
\text { and } \\
1 \text { Lane Minor } \\
(2-1)\end{array}$} & \multicolumn{3}{|c|}{$\begin{array}{c}2 \text { Lanes Major } \\
\text { and } \\
2 \text { Lanes Minor } \\
(2-2)\end{array}$} & \multicolumn{2}{|c|}{$\begin{array}{c}3 \text { Lanes Major } \\
\text { and } \\
1 \text { Lane Minor } \\
(3-1)\end{array}$} \\
\hline & $\mathrm{a}$ & $\mathrm{b}$ & $\mathrm{c}$ & $\mathrm{a}$ & $\mathrm{b}$ & $\mathrm{c}$ & $\mathrm{a}$ & $\mathrm{b}$ & $\mathrm{c}$ & $\mathrm{a}$ & $\mathrm{b}$ & $\mathrm{c}$ & $\mathrm{a} \quad \mathrm{b}$ & $\mathrm{c}$ \\
\hline 1 & 5.0 & 5.5 & 6.0 & 4.6 & 5.2 & 5.5 & 8.2 & 9.2 & 10.0 & 5.8 & 6.5 & 7.6 & $8.5 \quad 9.8$ & 10.9 \\
\hline 2 & 5.6 & 6.0 & 6.7 & 5.2 & 6.4 & 6.9 & 8.3 & 9.6 & 11.5 & 6.2 & 6.9 & 8.2 & 9.111 .9 & 12.7 \\
\hline 3 & 6.0 & 6.6 & 7.6 & 5.4 & 5.8 & 7.2 & 9.0 & 10.9 & 13.7 & 7.1 & 7.8 & 8.8 & 11.213 .8 & 16.2 \\
\hline 4 & 6.5 & 8.2 & 9.9 & 6.1 & 6.9 & 8.2 & 9.6 & 13.4 & 18.6 & 7.6 & 9.2 & 11.3 & 12.217 .5 & 20.2 \\
\hline 5 & 7.1 & 9.3 & 11.0 & 6.5 & 7.3 & 8.8 & 10.6 & 16.7 & 22.8 & 8.2 & 10.5 & 13.2 & 12.819 .1 & 23.9 \\
\hline 6 & 8.4 & 10.0 & 11.6 & 7.0 & 6.9 & 9.5 & 11.8 & 18.8 & 24.6 & 10.2 & 11.5 & 14.3 & 15.621 .5 & 26.1 \\
\hline 7 & 9.8 & 11.8 & 15.2 & 7.3 & 8.7 & 12.1 & 14.2 & 21.3 & 26.8 & 12.3 & 13.5 & 17.6 & 18.525 .4 & 30.5 \\
\hline 8 & 10.5 & 12.8 & 15.7 & 9.2 & 11.2 & 12.9 & 17.5 & 25.1 & 31.5 & 14.8 & 16.8 & 19.0 & 21.030 .9 & 35.8 \\
\hline 9 & 11.9 & 14.4 & 17.6 & 9.9 & 11.4 & 14.2 & 19.5 & 26.7 & 35.1 & 16.5 & 19.2 & 24.4 & 24.834 .5 & 42.1 \\
\hline 10 & 13.0 & 18.2 & 22.1 & 12.2 & 13.0 & 16.8 & 22.9 & 43.5 & 48.5 & 21.5 & 28.5 & 31.0 & 28.055 .6 & 65.1 \\
\hline
\end{tabular}

Note: $\mathrm{a}, \mathrm{b}$ and $\mathrm{c}$ represent scenarios with different turning volume percentage: $\mathrm{a}-(10 \%, 80 \%, 10 \%), \mathrm{b}$ $(20 \%, 60 \%, 20 \%)$, c - $(40 \%, 20 \%, 40 \%)$. 
Table 3: Average Minor Street Control Delays (s/veh) for 60 Scenarios (2-1 Configuration)

\begin{tabular}{|c|c|c|c|c|c|c|}
\hline \multirow{3}{*}{$\begin{array}{l}\text { Point from Critical } \\
\text { Curve }(2-1)\end{array}$} & \multicolumn{6}{|c|}{ Average Minor Street Control Delays (s/veh) } \\
\hline & \multicolumn{3}{|c|}{ 10\% Heavy Vehicle } & \multicolumn{3}{|c|}{ 20\% Heavy Vehicle } \\
\hline & $\mathrm{a}$ & $\mathrm{b}$ & $\mathrm{c}$ & a & $\mathrm{b}$ & $\mathrm{c}$ \\
\hline 1 & 7.7 & 8.0 & 8.8 & 7.5 & 7.0 & 8.5 \\
\hline 2 & 7.2 & 9.4 & 10.9 & 7.3 & 8.7 & 10.1 \\
\hline 3 & 7.9 & 10.0 & 12.6 & 7.5 & 9.0 & 11.0 \\
\hline 4 & 9.1 & 12.7 & 16.5 & 8.3 & 10.6 & 14.6 \\
\hline 5 & 9.7 & 15.3 & 20.2 & 8.8 & 14.0 & 16.8 \\
\hline 6 & 10.8 & 16.2 & 21.5 & 10.0 & 14.8 & 18.6 \\
\hline 7 & 12.6 & 18.3 & 23.1 & 11.9 & 16.1 & 20.4 \\
\hline 8 & 15.8 & 21.5 & 27.3 & 14.2 & 18.8 & 24.7 \\
\hline 9 & 17.7 & 24.5 & 30.3 & 16.0 & 22.0 & 25.6 \\
\hline 10 & 20.7 & 36.3 & 42.2 & 19.0 & 32.0 & 35.9 \\
\hline
\end{tabular}

Note: $\mathrm{a}, \mathrm{b}$ and $\mathrm{c}$ represent scenarios with different turning volume percentage: $\mathrm{a}-(10 \%, 80 \%$, $10 \%), \mathrm{b}-(20 \%, 60 \%, 20 \%), \mathrm{c}-(40 \%, 20 \%, 40 \%)$.

\section{EVALUATION}

\section{Delay Consistency}

Figure 4 plots the average control delay for the 1-1, 2-1, and 2-2 lane configurations for the case of $(40 \%, 20 \%, 40 \%)$ turning percentages. It can be seen from the figure that minor street traffic in the case of the 2-1 lane configuration experienced a significantly higher delay than those for the 1-1 and 2-2 lane configurations, especially at higher major street volumes. When major street traffic is at 1,100 vph or higher, the delay experienced by minor street traffic for the 2-1 lane configuration is about $100 \%$ higher than that of the 1-1 lane configuration, and $60 \%$ higher than that of the $2-2$ configuration. For example, when major street volume is at $1400 \mathrm{vph}$, the average delay for minor street traffic (at $80 \mathrm{vph}$, see Table 2) under the 2-1 configuration is about $48 \mathrm{~s} / \mathrm{veh}$. However, for the 2-2 lane configuration, the average delay for minor street traffic (at $115 \mathrm{vph}$, see Table 2) drops to $31 \mathrm{~s} / \mathrm{veh}$. There is no apparent reason for minor street traffic to experience $60 \%$ more delay simply because the minor street approach has one lane rather than two lanes. This suggests a possible need to adjust the two critical volumes for minor street traffic (e.g., $80 \mathrm{vph}$ for one lane and 115 $\mathrm{vph}$ for two lanes at major street traffic $=1400 \mathrm{vph}$ ) in order to make the two critical volumes more consistent.

Figure 4 also shows that the delay is lengthened by major street traffic volumes at an increasing rate. While it can be argued that when major street volumes are higher, minor street vehicles are expected to tolerate a higher delay, whether the magnitude of the increase is reasonable should be subjected to further scrutiny. For example, based on the current curve in four-hour warrant (Figure 1), for the 2-1 lane configuration, an unsignalized intersection with minor street traffic experiencing as low as $10 \mathrm{sec} / \mathrm{veh}$ (at $500 \mathrm{vph}$ major street traffic) has the same chance of being signalized as another intersection with minor street traffic experiencing as high as $48 \mathrm{sec} / \mathrm{veh}$ (at 1,400 vph major street traffic). This large difference suggests that the current standard is more likely to warrant an intersection with low major street volume, one that may not require signalization, rather than warrant one under high major street traffic, which evinces a greater need. 
Figure 4: Delay Comparisons for Different Volume Combinations and Lane Configurations at $(40 \%, 20 \%, 40 \%)$ Turning Percentages

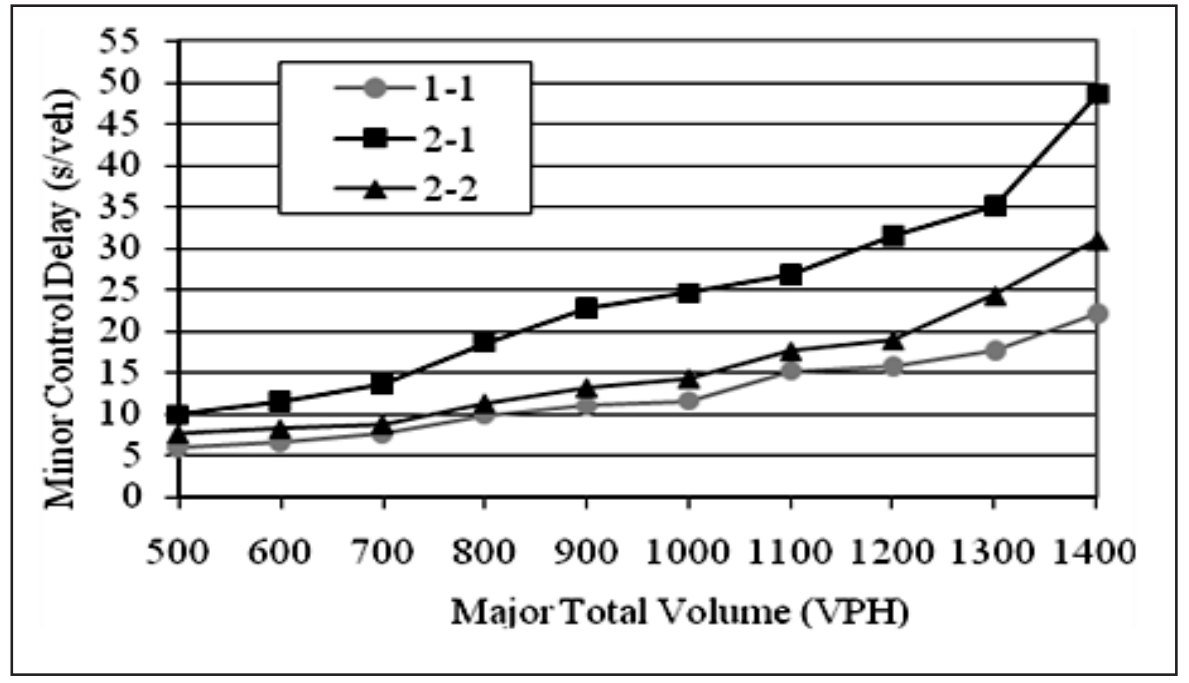

Sharing the Same Curve for 2-1 and 1-2 Lane Configurations

Figure 5 plots the control delays for the 2-1 and 1-2 lane configurations with $(20 \%, 60 \%, 20 \%)$ turning percentages. Since these two lane configurations share the same critical curve, the volume combinations used in the simulation are also the same.

It can be seen from the figure that the delay for the 2-1 lane configuration is significantly higher than the 1-2 counterpart. This suggests that a separate critical curve should perhaps be used for each lane configuration, especially at high major street volume, when the two configurations experienced more than $100 \%$ difference in delay.

Figure 5: Delay Comparisons for 1-2 and 2-1 Lane Configurations at $(20 \%, 60 \%, 20 \%)$ Turning Percentages

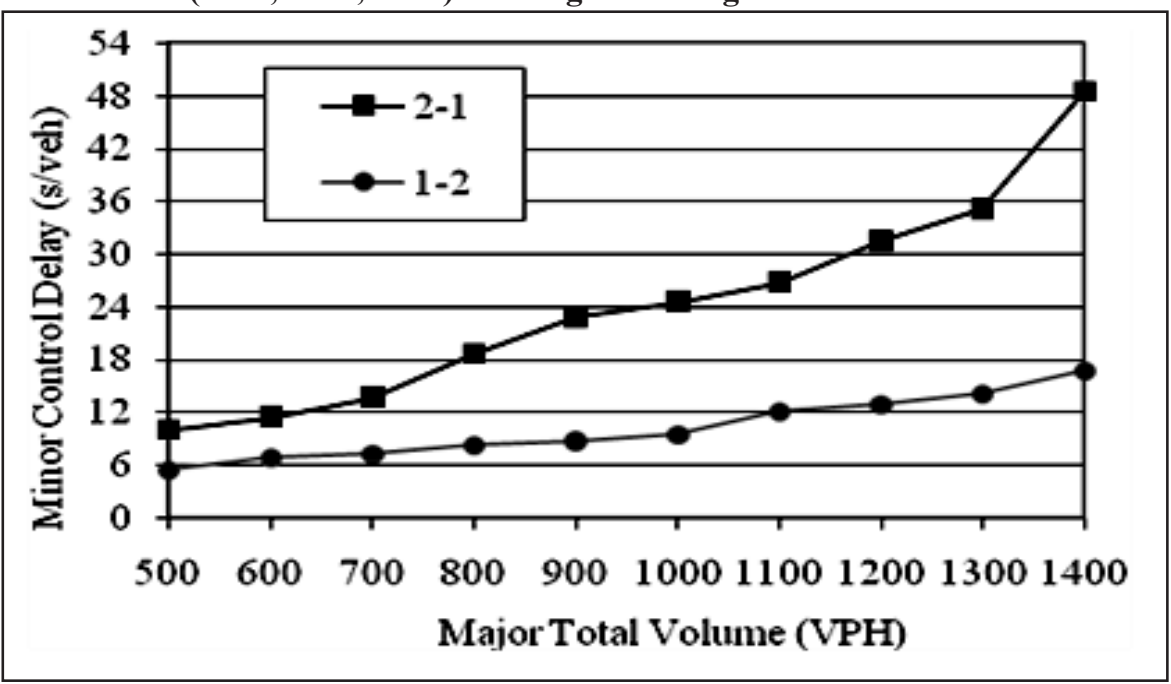




\section{Sharing the Same Curve for Two Lanes and Three or More Lanes}

The current four-hour warrant uses the same curve for both two lanes and more than two lanes. For evaluation purposes, a configuration with three major street lanes (i.e., 3-1) was created. Figure 6 shows the delay comparisons for the 3-1 and 2-1 lane configurations based on the $(10 \%, 80 \%, 10 \%)$ turning percentages. As expected, the average control delay for the three-lane case is consistently higher than the two-lane counterpart, as it is obvious that crossing a six-lane arterial is much harder than crossing one with four lanes. In recent years, mounting traffic congestion has led to a significant increase in the number of these six-lane arterials in urban areas. It is thus important to consider the impact of two additional lanes on minor street traffic, and possibly create a separate set of critical volumes for each lane configuration.

Figure 6: Delay Comparisons Between 3-1 and 2-1 Lane Configurations at $(10 \%, 80 \%, 10 \%)$ Turning Percentages

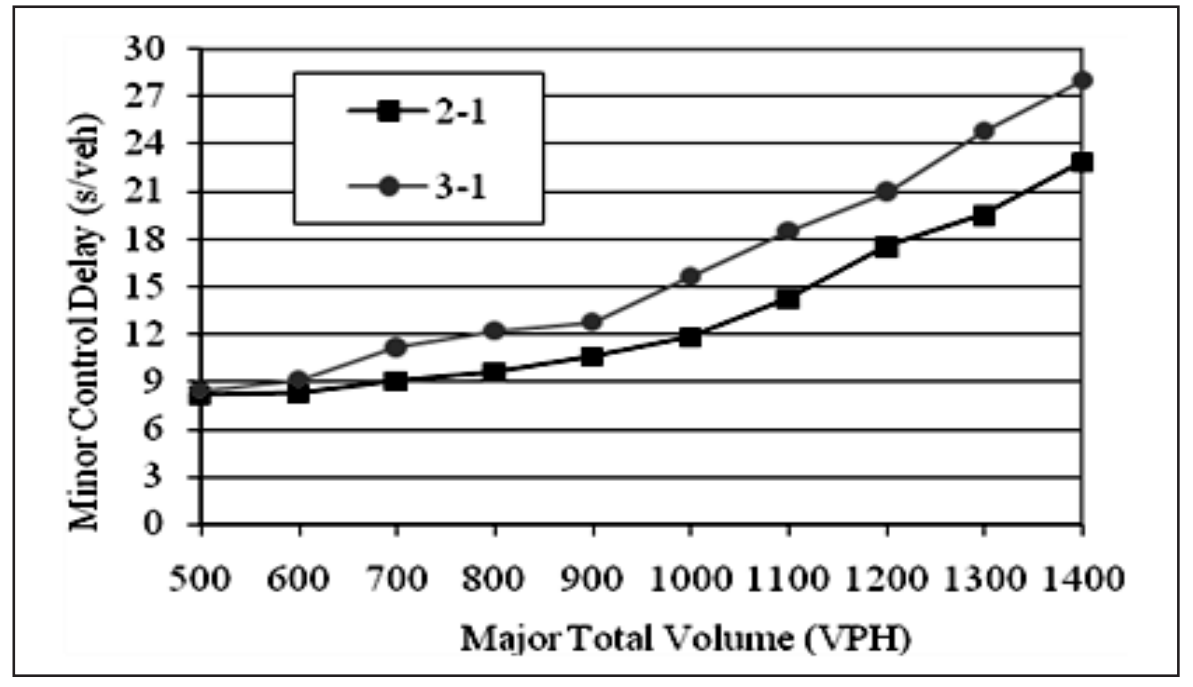

\section{Turning Volume Percentages}

Depending on local conditions, an unsignalized intersection can experience a wide range of turning movement percentages, which can have a considerable impact on minor street operation. The current standard does not consider these turning percentages. Thus, theoretically, an intersection with $100 \%$ right turns is treated the same as one with $100 \%$ left turns, even though the latter is likely to experience a much higher delay while the former may only need to increase right-turn opportunities, such as by adding a right-turn bay rather than signalization.

Figures 7 (a) to (d) compares the control delays for three turning percentages ranging from low to high left- and right-turn vehicles for the 1-1, 1-2, 2-1, and 2-2 lane configurations, respectively. As expected, the higher the left- and right-turn percentages, the higher the average delay experienced by the minor street vehicles. The difference also becomes increasingly larger with higher major street volumes. These observations are consistent for all four of the lane configurations. The results suggest a possible need to consider turning percentages in the four-hour warrant.

\section{Heavy Vehicle Percentages}

Figures 8 (a) to (c) compare the control delays for three heavy vehicle percentages ranging from low to high for three different left- and right-turn vehicle percentages, respectively. The same percentages are assumed for both minor and major streets. The results show that, as expected, the 
Figure 7: Delay Comparison - Different Turning Traffic Percentages

(a) 1-1

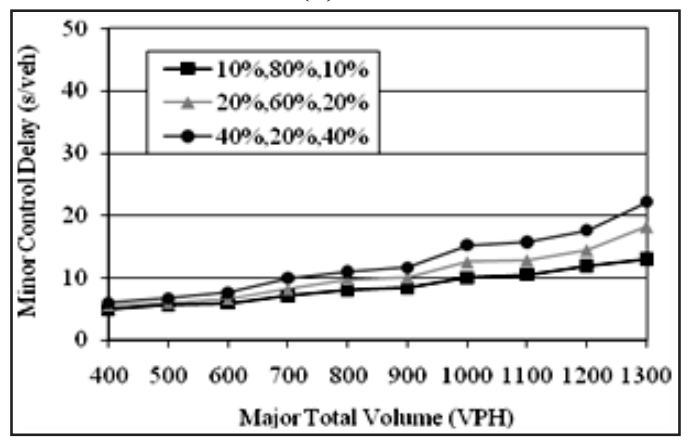

(c) 2-1

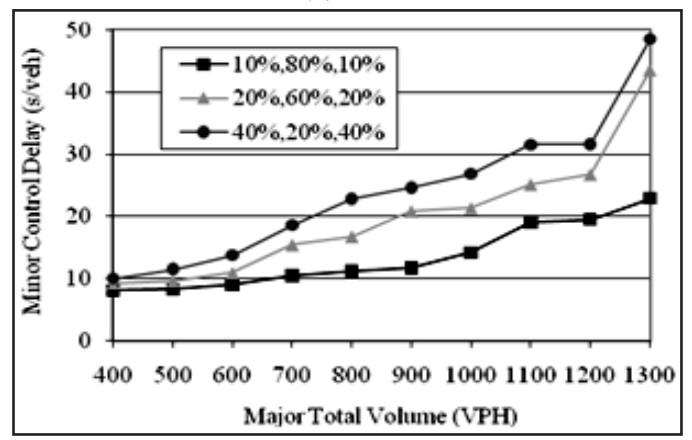

(b) 1-2

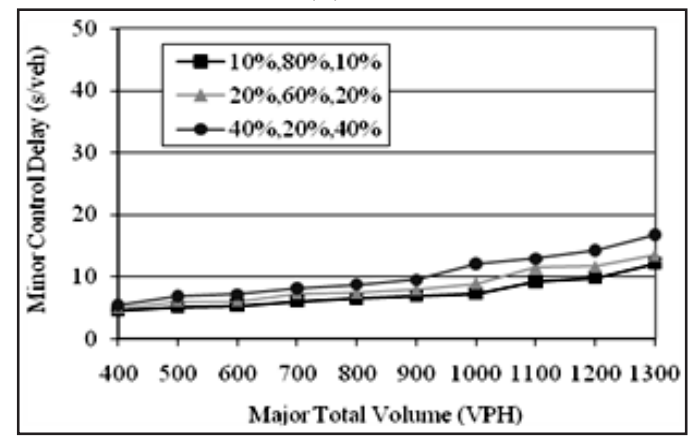

(d) 2-2

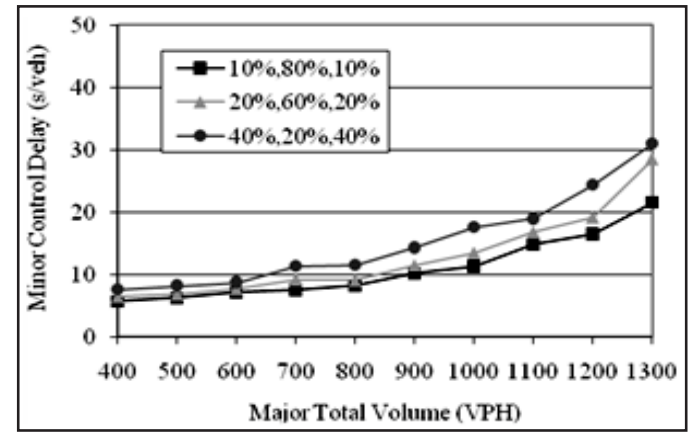

Figure 8: Delay Comparison - Different Heavy Vehicle Percentages

(a) $10 \%, 80 \%, 10 \%$

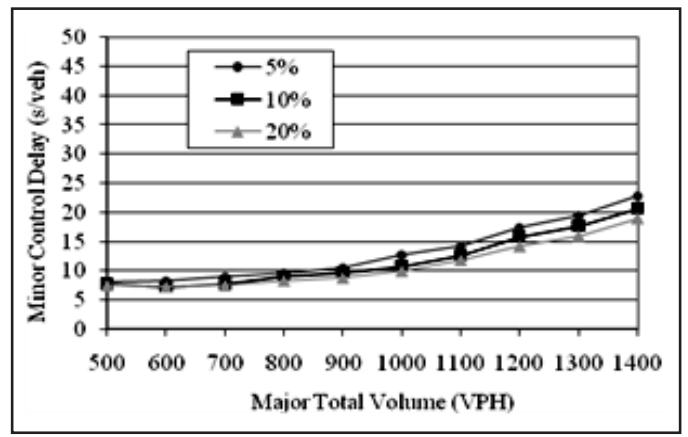

(b) $20 \%, 60 \%, 20 \%$

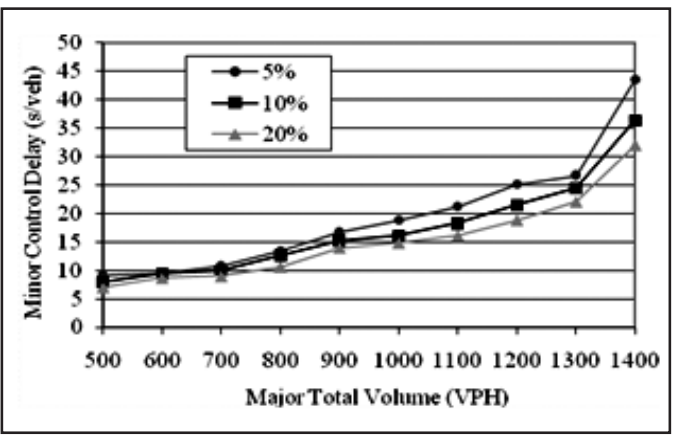

(c) $40 \%, 20 \%, 40 \%$

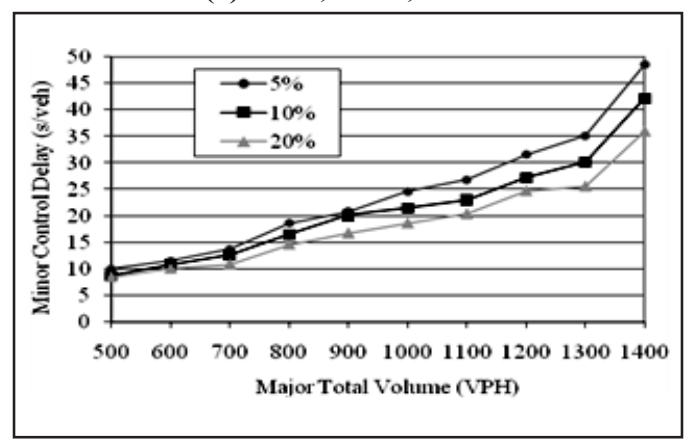


average delay for minor street traffic increases with increasing heavy vehicle percentage, especially at higher turning volumes. It should be recognized that the difference in delay in this case is not as large simply because the percentages evaluated are not significantly different $(15 \%$ between the lowest and highest percentage) to reflect the more typical range of heavy vehicles on local streets. In other words, it should not be interpreted as heavy vehicles having less of an impact than, for example, turning percentages.

\section{CONCLUSIONS AND RECOMMENDATIONS}

Today's advances in traffic simulation software provide opportunities for the reevaluation and revision of the decades old traffic standards currently in effect. This paper has presented results from a simulation evaluation of the critical volume curves of the four-hour signal warrant based on the average control delay experienced by minor street traffic. In this study, CORSIM was used as the evaluation tool to simulate a two-way stop-controlled intersection for five different lane configurations under various combinations of major and minor street volumes. The results show that:

1. The delays are significantly inconsistent along the different volume combinations of major and minor streets and among the different lane configurations evaluated.

2. There is a major difference in the delay experienced by minor street traffic under the two lane configurations (2-1 and 1-2) that currently share the same critical curves, suggesting a possible need to create a separate critical curve for each.

3. Whether the major street has four or six lanes has a major impact on minor street delay, suggesting a possible need to have separate critical curves for four-lane and six-lane arterials, especially in light of the increasing number of six-lane arterials in urban areas.

4. The percentages of left- and right-turn vehicles, which are not considered in the current four-hour warrant, have a significant impact on minor street delay.

5. The percentages of heavy vehicles, which are not currently considered in any of the existing warrants, have a significant impact on traffic operations at unsignalized intersections.

The above findings are based on the current standards for low-speed major streets (i.e., speeds of up to $40 \mathrm{mph}$ for major street approach, which are normal conditions defined in MUCTD). The impacts for high-speed major streets (i.e., speeds of above $40 \mathrm{mph}$ for major street approach) can be similarly evaluated. The findings of this study provide some preliminary evidence of the need to revisit the current standards in the four-hour warrant, and to perform further research to possibly refine them in order to better identify intersections that merit signalization. It is understood that various factors (e.g., empirical values, judgments) went into the establishment of the MUTCD'S critical vehicular volumes, which were not simply developed based on numerical analysis. It is also recognized that the signal warrants should generally be kept as simple as possible, however, standards that can lead to poor decisions should be reviewed and modified as needed. This is especially true for those factors that can be incorporated without significantly complicating the application, such as adjusting for more appropriate volume combinations and having separate critical curves for the 1-2 and 2-1 lane configurations, both of which can potentially achieve a more consistent traffic experience for motorists.

\section{References}

Al-Omari, B.H. and R.F. Benekohal. "Hybrid Delay Models for Unsaturated Two-Way Stop Controlled Intersections." Journal of Transportation Engineering ASCE 125(4), (1999): 291-296.

Chandra, S., A. Agrawal, and A. Rajamma. "Microscopic Analysis of Service Delay at Uncontrolled Intersections in Mixed Traffic Conditions." Journal of Transportation Engineering ASCE 135(6), (2009): 323-329. 
ITT Systems and Sciences Corporation. CORSIM User's Manual, Version 1.04. Federal Highway Administration (FHWA), U.S. Department of Transportation, Washington, D.C., 1998.

Federal Highway Administration (FHWA), U.S. Department of Transportation. Manual on Uniform Traffic Control Devices. Washington, D.C., 2009.

Kell, J.H. "Intersection Delay Obtained by Simulating Traffic on a Computer." Highway Research Record 15, (1963): 73-97.

Park, B., M.N. Rouphail, and E.J. Hummer. "Probabilistic Approach to Implementing Traffic Signal Warrants.” Journal of Transportation Engineering ASCE 126(4), (2000): 332-342.

Sampson, J.D. “Queue-based Traffic Signal Warrants.” Institute of Transportation Engineer ITE Journal 69(4), (1999): 39.

Texas Transportation Institute (TTI). Revising the Traffic Signal Warrants to Better Accommodate Pedestrians and Cyclists. College Station, Texas, 2001.

Transportation Research Board (TRB). Highway Capacity Manual. Washington, D.C., 2000.

Xuesong Zhu obtained his bachelor's and master's degrees in civil engineering from Tongji University, China, and his Ph.D. degree in transportation engineering from Florida International University. He is currently working as a transportation engineer with AECOM USA.

Albert Gan is an associate professor with the department of civil and environmental engineering at Florida International University. His areas of research have included traffic engineering, intelligent transportation systems (ITS), transit planning, demand modeling, and highway safety.

David Shen is a professor with the department of civil and environmental engineering at Florida International University. Dr. Shen's research interests center on guideway transit and transportation facility planning and design with special emphasis on intermodal guideway public transit systems. 